SECTION 7. Mechanics and machine construction.

Manat Beyshenovich Tlebayev

Doctor of engineering sciences, Professor, Academician of Kazakh National Academy of Natural Sciences, Head of the department «Computer engineering and Informatics» Taraz State University named after M.Kh. Dulati, Kazakhstan

Pavel Nikolayevich Shevtsov student

Taraz State University named after M.Kh. Dulati, Kazakhstan pasha369@mail.ru

\title{
DEVELOPMENT OF MATHEMATICAL MODELS AND COMPUTER SIMULATION OF EXTRUSION PROCESS IN THE ZONE DOSING
}

\author{
Abstract: In this research, a model is proposed for calculation of the characteristics of \\ the extrusion process. \\ Key words: extrusion, model, polymer, temperature, auger.

\section{РАЗРАБОТКА МАТЕМАТИЧЕСКОЙ МОДЕЛИ И КОМПЬЮТЕРНОЕ МОДЕЛИРОВАНИЕ ПРОЦЕССА ЭКСТРУЗИИ В ЗОНЕ ДОЗИРОВАНИЯ}

\author{
Аннотация: $B$ данном исследовании предлагается модель расчета \\ характеристик проиесса экструзии. \\ Ключевые слова: экструзия, модель, полимер, температура, шнек.
}

\section{Описание технологии процесса экструзии}

Экструзия - способ получения изделий или полуфабрикатов из полимерных материалов неограниченной длины путем выдавливания расплава полимера через формующую головку нужного профиля. Экструзия, наряду с литьем пластмасс под давлением, является одним из самых популярных методов изготовления пластмассовых изделий. Экструзии подвергаются практически все основные типы полимерных материалов, как термопласты, таки и реактопласты, а также эластомеры.[1]

В основном для экструзии пластмасс применяют шнековые, или червячные экструдеры. Также существуют дисковые экструдеры. Для успешного производства продукции методом экструзии недостаточно только одного экструдера. Кроме него необходимо иметь еще несколько единиц оборудования, вместе составляющих экструзионную линию. Экструдер (от лат. extrudo - выталкиваю), машина для размягчения (пластикации) материалов и придания им формы путём продавливания через профилирующий инструмент (экструзионную головку), сечение которого соответствует конфигурации изделия. В экструдере получают главным образом изделия из термопластичных полимерных материалов (пластических масс), используют их также для переработки резиновых смесей. С помощью экструдеров изготовляют плёнки, листы, трубы, шланги, изделия сложного профиля и др., наносят тонкослойные покрытия на бумагу, картон, ткань, фольгу, а также изоляцию на провода и кабели. Экструдеры применяют, кроме того, для получения гранул, подготовки композиций для каландрирования, формования металлических изделий и для других целей.[2-5] 


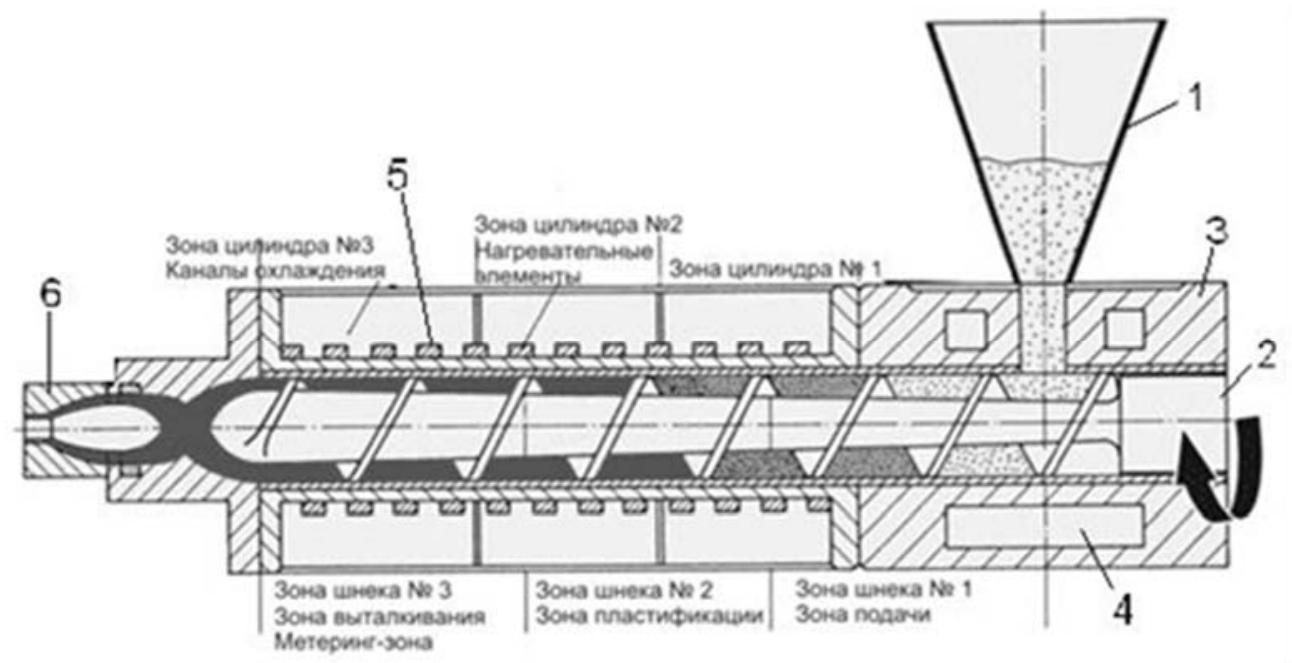

Рисунок 1 - Схема одношнекового экструдера.

1-бункер; 2-червяк(шнек); 3-цилиндр; 4-полость для циркуляции воды; 5нагреватель; 6-формирующая головка с адаптером.

Наиболее простым оборудованием для экструзии является одношнековый (одночервячный) (рис.1). Такие экструдеры широко применяются для производства пленок, листов, труб, профилей, в качестве одной из составных частей линийгрануляторов и т.д. Шнек экструдера обычно состоит из трех зон: загрузки, сжатия и дозирования. Зона загрузки транспортирует полимер от отверстия под бункером к более горячим секциям цилиндра. Зона сжатия - это зона, где уменьшается глубина нарезки, а значит, и объем витка, что приводит к сжатию плавящихся гранул. Главный эффект сжатия - увеличение сдвигового воздействия на расплавленный полимер, обусловленного взаимным движением поверхности шнека относительно стенки цилиндра. Это улучшает смешение, увеличивает разогрев от трения и приводит к более однородному распределению тепла в расплаве. Назначение последней зоны шнека дальнейшая гомогенизация расплава, однородное дозирование его через формующую головку, сглаживание пульсации на выходе. Шнек затем продавливает расплавленный полимер через фильеру, которая определяет конечную форму. Шнеки современных экструдеров часто имеют сложную геометрическую форму и неравномерную нарезку, подбираемую специально под конкретный материал и режим работы. Одношнековые экструдеры могут иметь не только цилиндрическое, но и коническое исполнение шнека и гильзы. Конический шнек позволяет эффективнее осуществить перемешивание компаунда, быстрее поднять давление расплава и сделать машину более компактной и производительной.[2-7]

Ключевую роль в механике движения материала внутри экструдера во всех его фазах играют силы трения материала и расплава о стенки цилиндра и шнека. Процессы эти весьма сложные, описываются системами дифференциальных уравнений, которые сегодня решаются при помощи математических компьютерных моделей.

Выходящий из фильеры расплавленный горячий материал в физическом смысле представляет собой высоковязкую жидкость. Поэтому скорость его выхода определяется давлением расплава и сопротивлением его движению в фильере. На выходе из фильеры скорости движения отдельных потоков расплава на выходе из фильеры должны быть одинаковы. Динамические свойства материала и его расплава определяются его физическим и химическим составом, а также температурой. Поэтому современные экструдеры снабжаются эффективными системами автоматического контроля и управления загрузкой компонентов, температурой, давлением расплава (скоростью вращения шнека).[4, 6-9] 
Важнейшими свойствами материалов, влияющими на работу экструдера в твердой фазе, являются насыпная плотность, сжимаемость, размеры и форма частиц, внутреннее и внешнее трение, склонность к агломерации, в расплавленном состоянии комплекса вязкостных характеристик.

Основными технологическими характеристиками одношнекового экструдера являются L, D, L/D, скорость вращения шнека $\mathrm{n}$, геометрический профиль шнека и степень сжатия (компрессии) - отношение объема одного витка червяка в зоне загрузки к объему одного витка в зоне дозирования. Короткошнековые экструдеры имеют $\mathrm{L} / \mathrm{D}=$ $12-18$, длинношнековые L/D> 30. Наиболее распространены экструдеры с L/D = 20-25. Показателем работы экструдера является его эффективность - отношение производительности к потребляемой мощности.[11]

Материалы. Большинство термопластов и композиций на их основе могут перерабатываться экструзией. Для этого достаточно, чтобы время пребывания расплава в экструдере при данной температуре было меньше времени термостабильности полимера при той же температуре. Наиболее широко применяется экструзия крупнотоннажных полимеров следующих типов. ПЭ, ПП, ПС ПК ПА, ПВХ (пластифицированный и непластифицированный), ПЭТФ а также смеси с неорганическими и полимерными наполнителями и более сложные композиции на их основе. Для экструзии применяются материалы и режимы переработки при которых ПТР меняется в пределах 0,3 - 12 г/10 мин, т.к. из маловязких расплавов невозможно получить сплошную экструзионную заготовку в виде пленки, трубы, профиля. Если же используются литьевые марки полимера, то из них можно получить экструзией лишь отдельные типы изделий, так как ПТР у них находится в пределах 0,8 - 20 г/10 мин. Так, трубы, кабельные покрытия производят из расплава полимера с ПТР от 0,3 до 1 г/10 мин. Это связано с выбором полимера большой молекулярной массы. Последняя определяет эксплуатационные свойства изделий - повышенные физико-механические характеристики. Пленки, листы изготавливают экструзией расплава с ПТР в пределах 1 - 4 г/10 мин. Дискретные изделия, производимые экструзией расплава с последующим раздувом в форме, получают из расплава с ПТР $=1,5-$ 7,0 г/10 мин. Ламинирование с помощью экструзии происходит при ПТР расплава в пределах 7 - 12 г/10 мин.

\section{Разработка моделирующего алгоритма}

Основным назначением зоны дозирования является придание расплаву, поступающему из зоны плавления, требуемых характеристик (гомогенность состава и свойств, нагрев до необходимой температуры, создание заданного давления) и продавливание его через формирующий инструмент с требуемой производительностью. Как правило, процессы в зоне дозирования можно рассматривать как чисто гидродинамические, характеризующиеся ламинарным режимом ввиду большой вязкости полимеров. В то же время, анализ процессов в этой зоне затруднен из-за сложности каналов в которых, имеет место течение расплава, интенсивного массообмена между отдельными секциями, ярко выраженной изотермичности процесса и достаточно сложного распределения давления в массе перерабатываемого материала.

При анализе работы зоны дозирования одночервячных экструдеров наибольшее развитие в настоящее время получило модельное представление развертки канала червяка на плоскость с обращением движения материального цилиндра. В такой модели рассматривается течение жидкой среды в прямоугольном канале под действием бесконечной плоскости, движущейся над каналом со скоростью $\mathrm{V}$ под углом $\varphi$. В общем виде решение данной задачи достигается совместным решением уравнений: движения 


$$
\rho\left(\frac{\partial V_{i}}{\partial t}+V_{j} \frac{\partial V_{i}}{\partial x_{j}}\right)=\rho f_{i}^{2}-\frac{\partial P}{\partial x_{j}}+\frac{\partial t_{i, j}}{\partial x_{j}}
$$

неразрывности (для несжимаемых сред):

$$
\sum \frac{\partial V_{i}}{\partial x_{i}}=0
$$

сохранения энергии:

$$
\rho C_{p}\left(\frac{\partial T}{\partial t}+V_{j} \frac{\partial T}{\partial x_{j}}\right)=\frac{\partial}{\partial x_{j}}\left(K-\frac{\partial T}{\partial x_{j}}\right)+t_{i, j} \frac{\partial V_{i}}{\partial x_{j}}
$$

реологического уравнения:

$$
t_{i, j}=f\left(\xi_{i, j}, \eta\right)
$$

при соответствующих граничных условиях. Путем математических преобразований можно получить формулу для расчета объемной производительности одношнекового экструдера с переменной глубиной нарезки спирального канала Q, в см $3 / c$, которую можно записать в виде:

$$
Q=\frac{A_{1} \cdot K \cdot n}{K+B_{1}+C_{1}}
$$

где $\mathrm{A}_{1}, \mathrm{~B}_{1}, \mathrm{C}_{1}$ постоянные соответственно прямого и двух обратных потоков:

$$
\begin{aligned}
& \mathrm{A} 1:=\frac{\pi^{3} \cdot(\mathrm{t}-\chi \cdot \mathrm{e}) \cdot \sigma}{\mathrm{a}+\mathrm{t}^{2} \cdot \mathrm{b}} \\
& \mathrm{B} 1:=\frac{\pi \cdot \mathrm{t} \cdot(\mathrm{t}-\chi \cdot \mathrm{e})}{12 \cdot \operatorname{Ln} \cdot\left(\mathrm{a}+\mathrm{t}^{2} \cdot \mathrm{b}\right)}
\end{aligned}
$$

где

- $\mathrm{t}$ - шаг нарезки, см;

- $\chi$ - число заходов нарезки шнека;

- $\sigma$ - коэффициент геометрических параметров шнека;

- $\mathrm{a}, \mathrm{b}$ - расчетные коэффициенты, $1 / \mathrm{cm}^{2}$;

- Ln - длина зоны сжатия шнека, см;

Поток утечки $\mathrm{C}_{1}$ обычно является очень малой величиной, не влияющей на производительность, им можно пренебречь. Расчетные коэффициенты можно найти по формулам: 


$$
\begin{aligned}
& \mathrm{a}:=\frac{\pi^{2}}{\mathrm{~h} 2 \cdot \mathrm{h} 3} \cdot\left[\frac{\mathrm{D} \cdot(\mathrm{h} 2-\mathrm{h} 3)}{2 \cdot h 2 \cdot h 3}-1\right] \\
& \mathrm{b}:=\frac{2.3}{(\mathrm{~h} 2-\mathrm{h} 3) \cdot \mathrm{D}^{3}} \cdot \log \left[\frac{\mathrm{h} 2 \cdot(\mathrm{D}+\mathrm{d} 2)}{\mathrm{h} 3 \cdot(\mathrm{D}+\mathrm{d} 1)}\right]+\frac{2 \cdot \mathrm{h} 2 \cdot \mathrm{h} 3+(\mathrm{h} 2+\mathrm{h} 3) \cdot \mathrm{D}}{2 \cdot \mathrm{D}^{2} \cdot \mathrm{h} 2^{2} \cdot \mathrm{h} 3^{2}}
\end{aligned}
$$

где D - диаметр шнека, cм; h2, h3 - глубина нарезки спирального канала шнека в начале и конце зоны сжатия, см; d1, d2 - диаметры сердечника шнека у загрузочной воронки и в начале зоны сжатия, см;

Формула (1) позволяет рассчитать производительность экструдера, у которого шаг постоянный, а глубина нарезки меняется. Тогда производительность будет зависеть от частоты вращения шнека и эффективной вязкости расплава, глубина нарезки спирального канала шнека. Эти параметры следует считать основными в технологическом процессе экструзии. Сюда следует добавить также температуры по зонам цилиндра и головки, от которых зависит вязкость расплава. Эти температуры выбираются на основе температур фазовых переходов, получаемых из термомеханических кривых. Формулу (1) можно использовать для предварительного определения производительности экструдера. Максимальное давление расплава Pm в конце шнека является одним из важнейших технологических параметров, от которого зависит качество экструдера и производительность машины. Величину Pm, Па можно приблизительно подсчитать:

$$
\mathrm{Pm}:=\frac{\pi \cdot \mathrm{D} \cdot \mathrm{Lg} \cdot \mu \mathrm{v} \cdot \mathrm{n}}{\mathrm{h} 3^{2} \cdot \operatorname{tg} \phi 60}
$$

где $\mathrm{Lg}=(3 \div 5) \mathrm{t}-$ длина зоны дозирования, см; t $=(0.8 \div 1.2) \mathrm{D}$ - шаг нарезки, см.

Величина Pm превышает действительное давление Pd расплава перед головкой в $1.2 \div 1.5$ раза. От величины скорости сдвига расплава в канале шнека $\gamma\left(\mathrm{c}^{-1}\right)$ зависит величина эффективной вязкости расплава.

$$
\gamma=\pi \mathrm{Dn} / \mathrm{h}
$$

На основании рассмотренных математических зависимостей составляем блоксхему решения задачи. Разработанная блок-схема приведена на рисунке 2. 


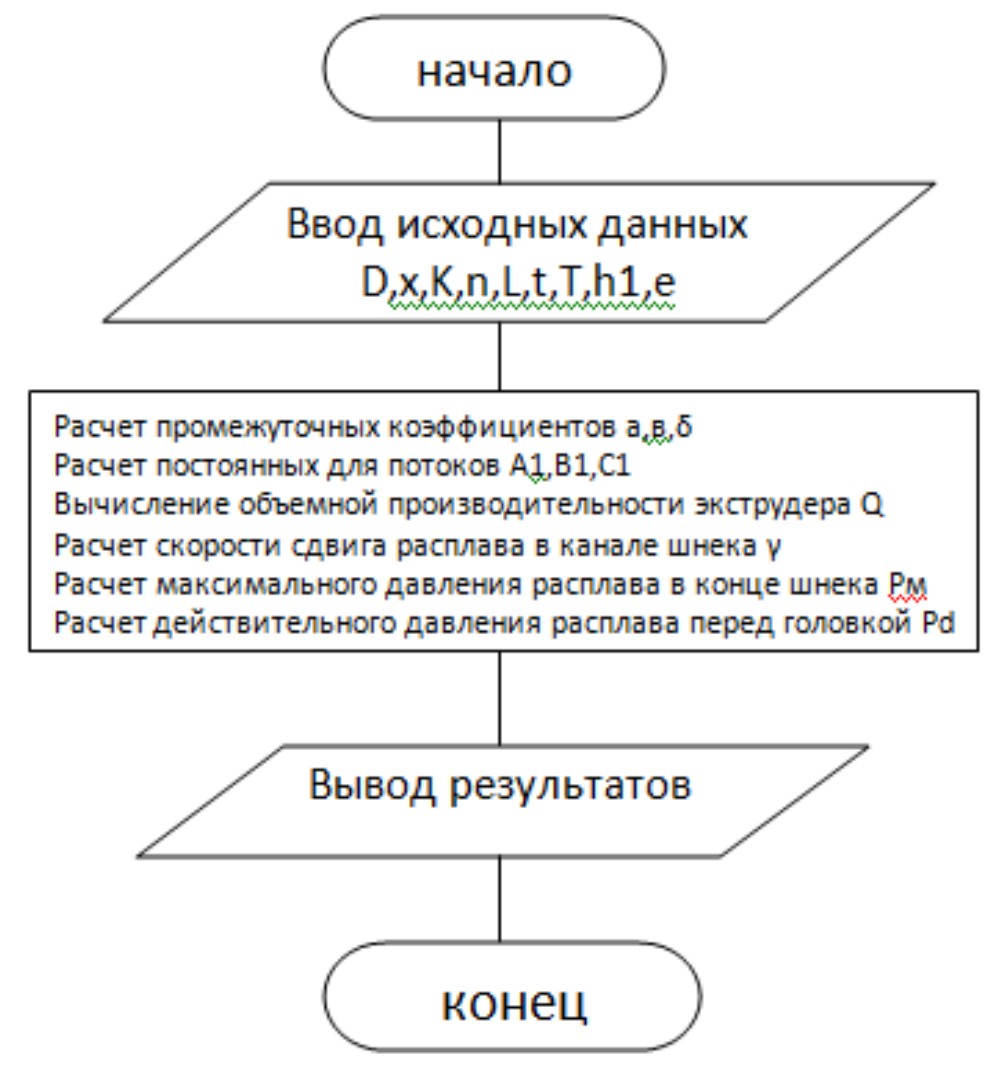

Рисунок 2 - Блок-схема решения задачи

\section{Составление программы и решение ее на ЭВМ}

Решение поставленной задачи будем выполнять в Delphi в соответствии с разработанным алгоритмом

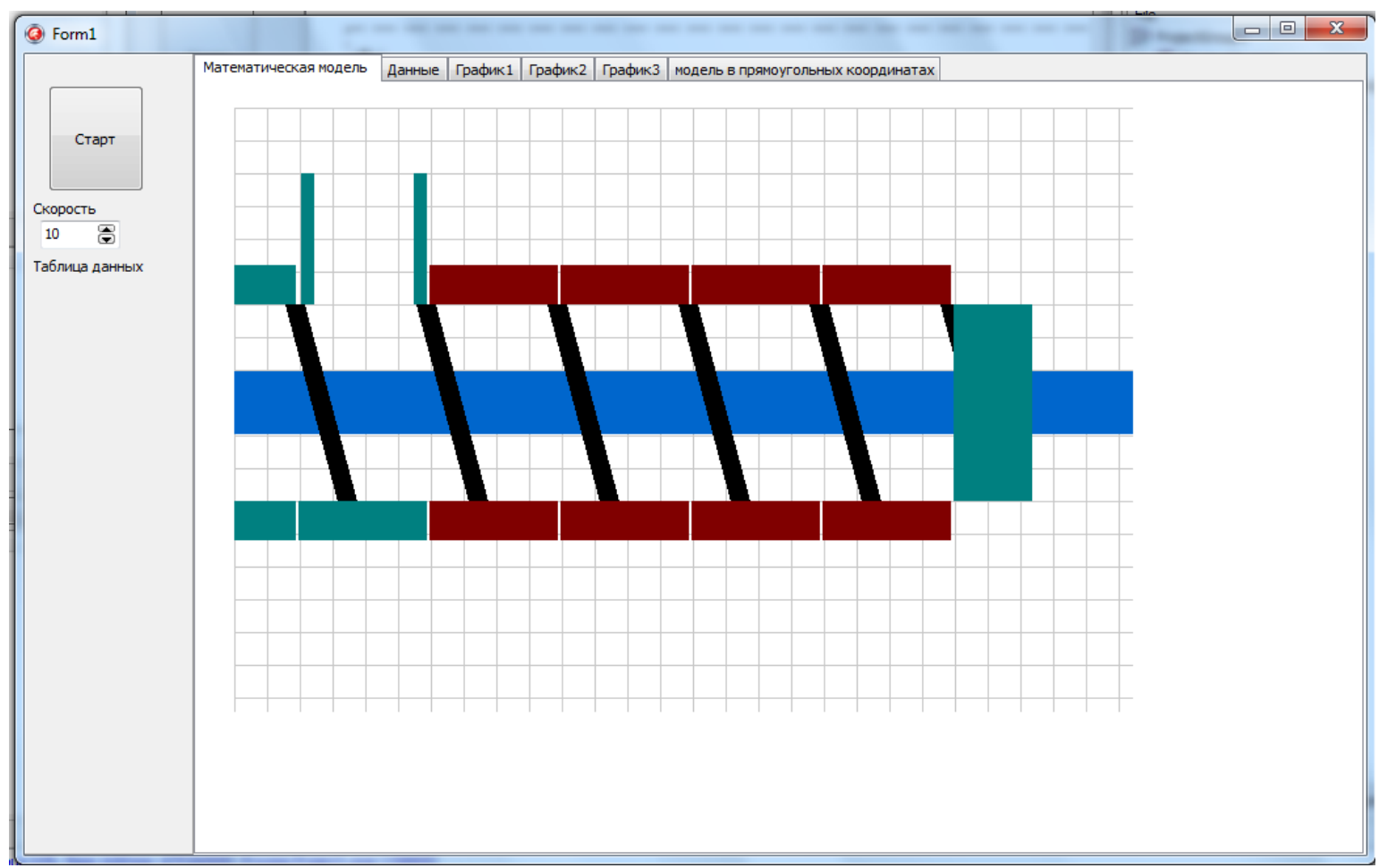

Рисунок 3 - Основное окно программы 
Задаем начальные условия:

$\begin{array}{ll}\mathrm{D}:=20 & \text { Диаметр шнека, см } \\ \gamma:=1 & \text { Число заходов шнека } \\ \mathrm{n}:=30 & \text { Частота вращений шнека, об/мин } \\ \mathrm{L}:=35 \mathrm{D} & \text { Длина шнека } \\ \mathrm{K}:=0.0055 & \text { Коэф-т формы головки } \\ \mathrm{t}:=1.1 . \mathrm{D} & \text { Шаг нарезки, см } \\ \mathrm{t}=22 & \text { Температура переработки } \\ \mathrm{T}:=180 & \text { Глубина канала в начале зоне загрузки, с } \\ \mathrm{h} 1:=0.15 \mathrm{D} & \\ \mathrm{h} 1=3 & \text { Ширина гребня шнека, см } \\ \mathrm{e}:=0.09 \mathrm{D} & \end{array}$

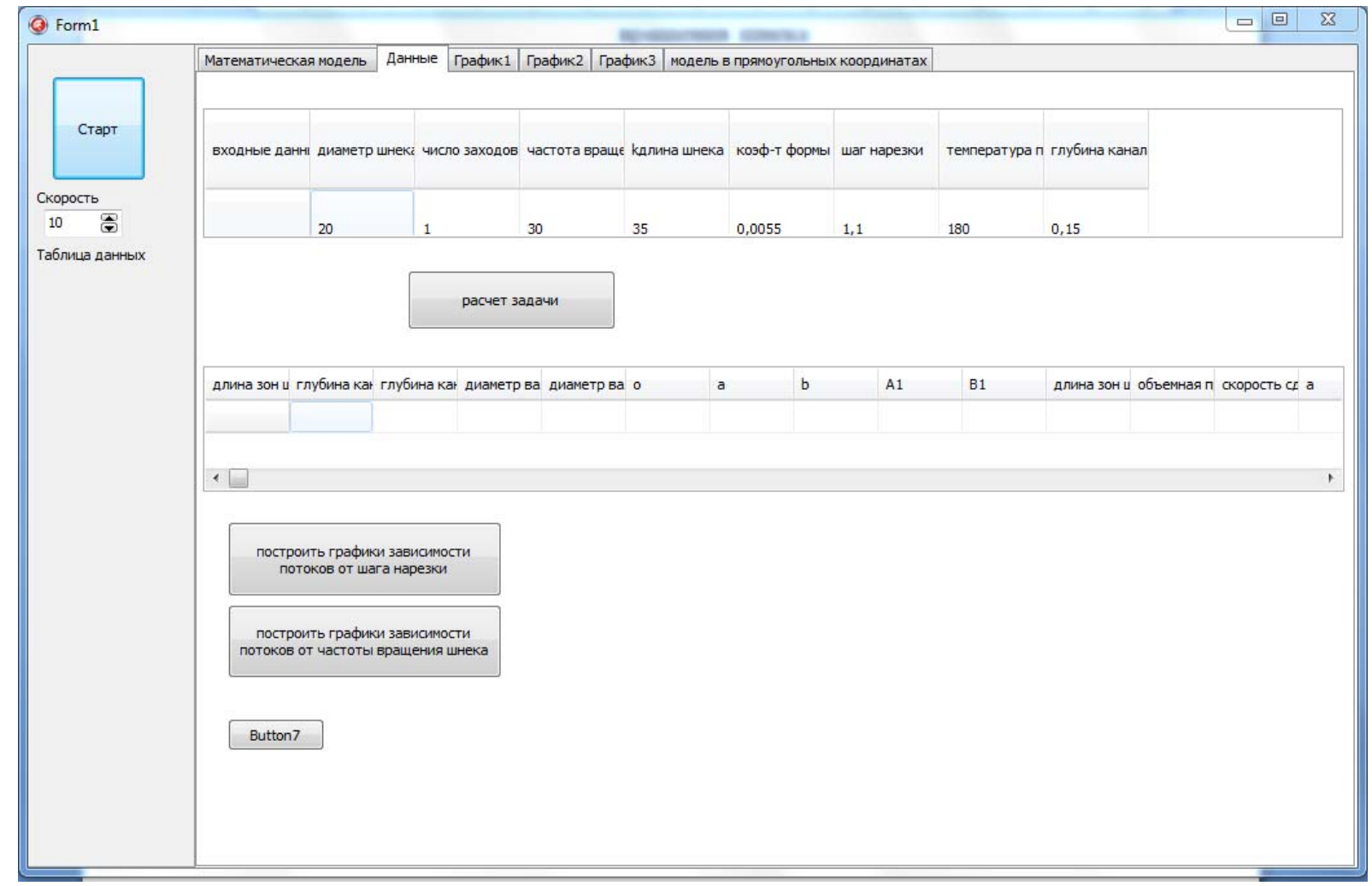

Рисунок 4 - Исходные данные

Для заданного материала ПЭНП принимаем степень уплотнения $\mathrm{i}=2$. Рассчитываем необходимые промежуточные параметры: 
Дпина зон шнека

$$
\operatorname{Ln}:=0.7 \cdot \mathrm{L} \quad \mathrm{Lc}:=\mathrm{L}-\mathrm{Ln}
$$

Глубина канала в зоне дозирования

$$
h 3:=0.5 \cdot\left[D-\sqrt{D^{2}-\frac{4 \cdot h 1}{i}(D-h 1)}\right]
$$

Глубина канала в начале зоны сжатия

$$
\mathrm{h} 2:=\mathrm{h} 1-\frac{\mathrm{h} 1-\mathrm{h} 3}{\mathrm{~L}} \cdot \mathrm{Lc}
$$

Диаметры вала в соответствующих точках

$$
\mathrm{d} 1:=\mathrm{D}-2 \cdot \mathrm{h} 1
$$

Находим промежуточные коэффициенты:

$$
\begin{aligned}
& \sigma:=1-\left[\frac{6 \cdot 9 \cdot \mathrm{D}}{2(\mathrm{~h} 2-\mathrm{h} 1)} \cdot \log \left(\frac{\mathrm{h} 2}{\mathrm{~h} 3}\right)-\frac{\mathrm{D}^{2}}{2 \cdot \mathrm{h} 2 \cdot \mathrm{h} 3}\right] \\
& \mathrm{a}:=\frac{\pi^{2}}{\mathrm{~h} 2 \cdot \mathrm{h} 3} \cdot\left[\frac{\mathrm{D} \cdot(\mathrm{h} 2-\mathrm{h} 3)}{2 \cdot \mathrm{h} 2 \cdot \mathrm{h} 3}-1\right] \\
& \mathrm{b}:=\frac{2.3}{(\mathrm{~h} 2-\mathrm{h} 3) \cdot \mathrm{D}^{3}} \cdot \log \left[\frac{\mathrm{h} 2 \cdot(\mathrm{D}+\mathrm{d} 2)}{\mathrm{h} 3 \cdot(\mathrm{D}+\mathrm{d} 1)}\right]+\frac{2 \cdot \mathrm{h} 2 \cdot \mathrm{h} 3+(\mathrm{h} 2+\mathrm{h} 3) \cdot \mathrm{D}}{2 \cdot \mathrm{D}^{2} \cdot \mathrm{h}^{2} \cdot \mathrm{h}^{2}}
\end{aligned}
$$

Находим постоянные прямого и обратного потоков:

$$
\begin{aligned}
& \mathrm{A} 1:=\frac{\pi^{3} \cdot(\mathrm{t}-\chi \cdot \mathrm{e}) \cdot \sigma}{\mathrm{a}+\mathrm{t}^{2} \cdot \mathrm{b}} \\
& \mathrm{B} 1:=\frac{\pi \cdot \mathrm{t} \cdot(\mathrm{t}-\chi \cdot \mathrm{e})}{12 \cdot \operatorname{Ln} \cdot\left(\mathrm{a}+\mathrm{t}^{2} \cdot \mathrm{b}\right)}
\end{aligned}
$$

Согласно формуле (1) вычисляем объемную производительности экструдера Q, см3/сек:

$$
\mathrm{Q}:=\frac{\mathrm{A} 1 \cdot \mathrm{K} \cdot \mathrm{n}}{60 \cdot(\mathrm{K}+\mathrm{B} 1+\mathrm{C} 1)}
$$

Далее рассчитываем скорость сдвига расплава в канале шнека. 


$$
\gamma:=\frac{\pi \cdot \mathrm{D} \cdot \mathrm{n}}{60 \cdot \mathrm{h} 3}
$$

Необходимые для дальнейших расчетов коэффициенты а и b определяем с использованием графика температурной зависимости для материала ПЭНП. Берем координаты двух точек для линии температуры T=180.

$$
\begin{array}{llll}
\mu 1:=\log (1800) & \mu 1=3.255 & \gamma 1:=\log (20) & \gamma 1=1.301 \\
\mu 2:=\log (500) & \mu 2=2.699 & \gamma 2:=\log (350) & \gamma 2=2.544
\end{array}
$$

Составляем уравнение прямой, проходящей через две точки.

$$
\frac{\log (\mu)-\mu 1}{\mu 2-\mu 1}=\frac{\log (\gamma)-\gamma 1}{\gamma 2-\gamma 1}
$$

После преобразования уравнения определяем коэффициенты.

$$
\begin{aligned}
& \underset{m}{\mathrm{a}}:=\frac{\mu 2-\mu 1}{\gamma 2-\gamma 1} \\
& \stackrel{\mathrm{m}}{\mathrm{b}}:=\mathrm{a} \cdot \gamma 1+\mu 1
\end{aligned}
$$

Находим эффективную вязкость расплава в зазоре шнека.

$$
\mu \mathrm{v}:=10^{\gamma \mathrm{v}^{\mathrm{a}} \cdot \mathrm{b}}
$$

Находим длину зоны дозирования и тангенс угла наклона.

$$
\operatorname{Lg}:=4 \cdot \mathrm{Lg}=88 \quad \operatorname{tg} \phi:=\frac{\mathrm{t}}{\pi \cdot \mathrm{D}}
$$

Согласно формуле (2) определяем максимальное давление расплава, Па:

$$
\operatorname{Pm}:=\frac{\pi \cdot \mathrm{D} \cdot \operatorname{Lg} \cdot \mu \mathrm{v} \cdot \mathrm{n}}{\mathrm{h} 3^{2} \cdot \operatorname{tg} \phi \cdot 60}
$$

Определяем действительное давление расплава перед головкой, Па:

$$
\operatorname{Pd}:=\frac{\operatorname{Pm}}{1.5}
$$

\section{Анализ полученных результатов}

В результате проведенных расчетов для заданных исходных данных были получены следующие результаты производительности одношнекового экструдера: Объемная производительность: $557 \mathrm{~cm}^{3} /$ сек. Действительное давление расплава перед головкой составляет 12774 Па. 


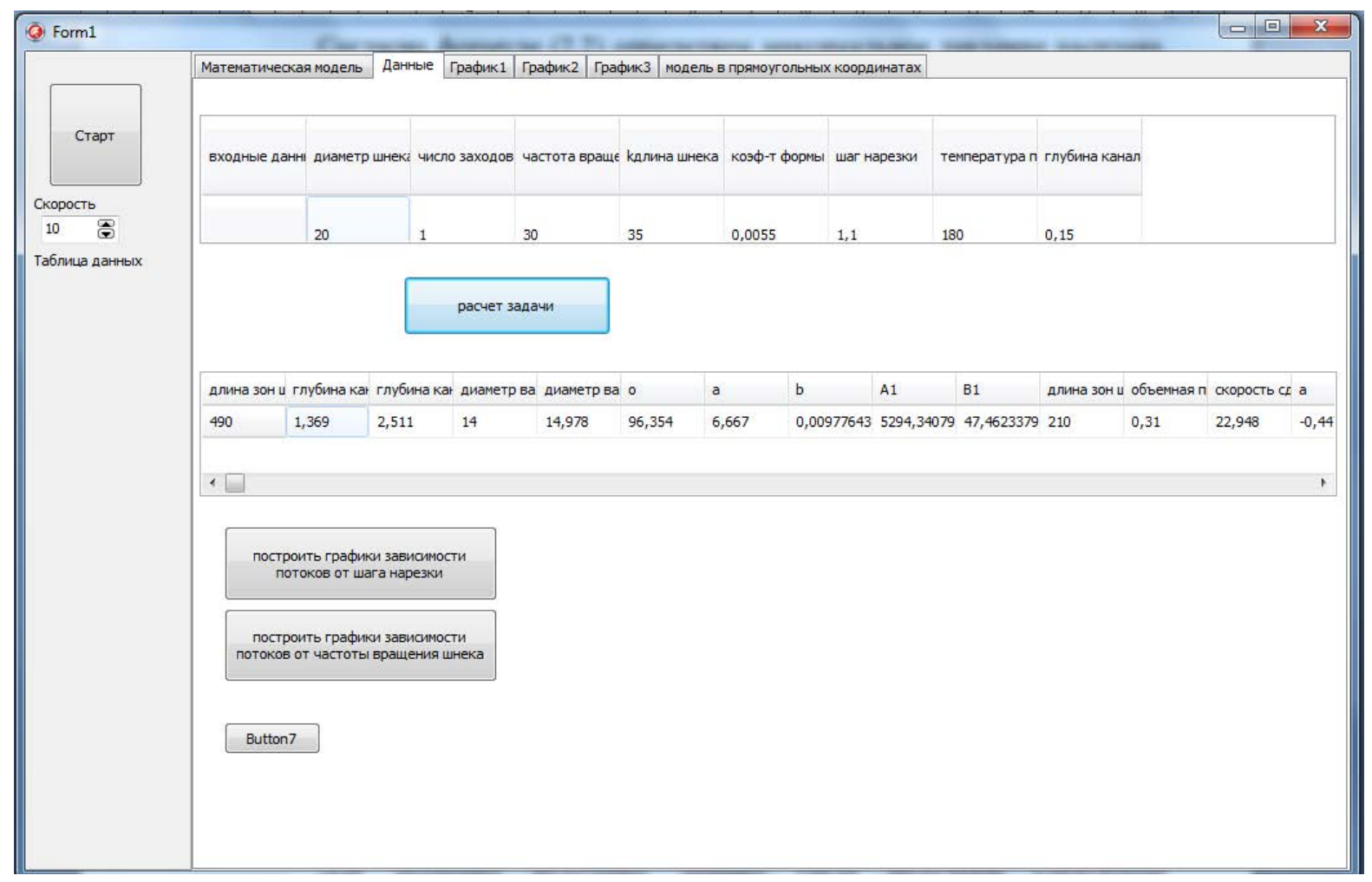

Рисунок 5 - Окно программы с вычисленными значениями

Для заданных исходных данных были получены следующие результаты производительности при изменении частоты вращения шнека.

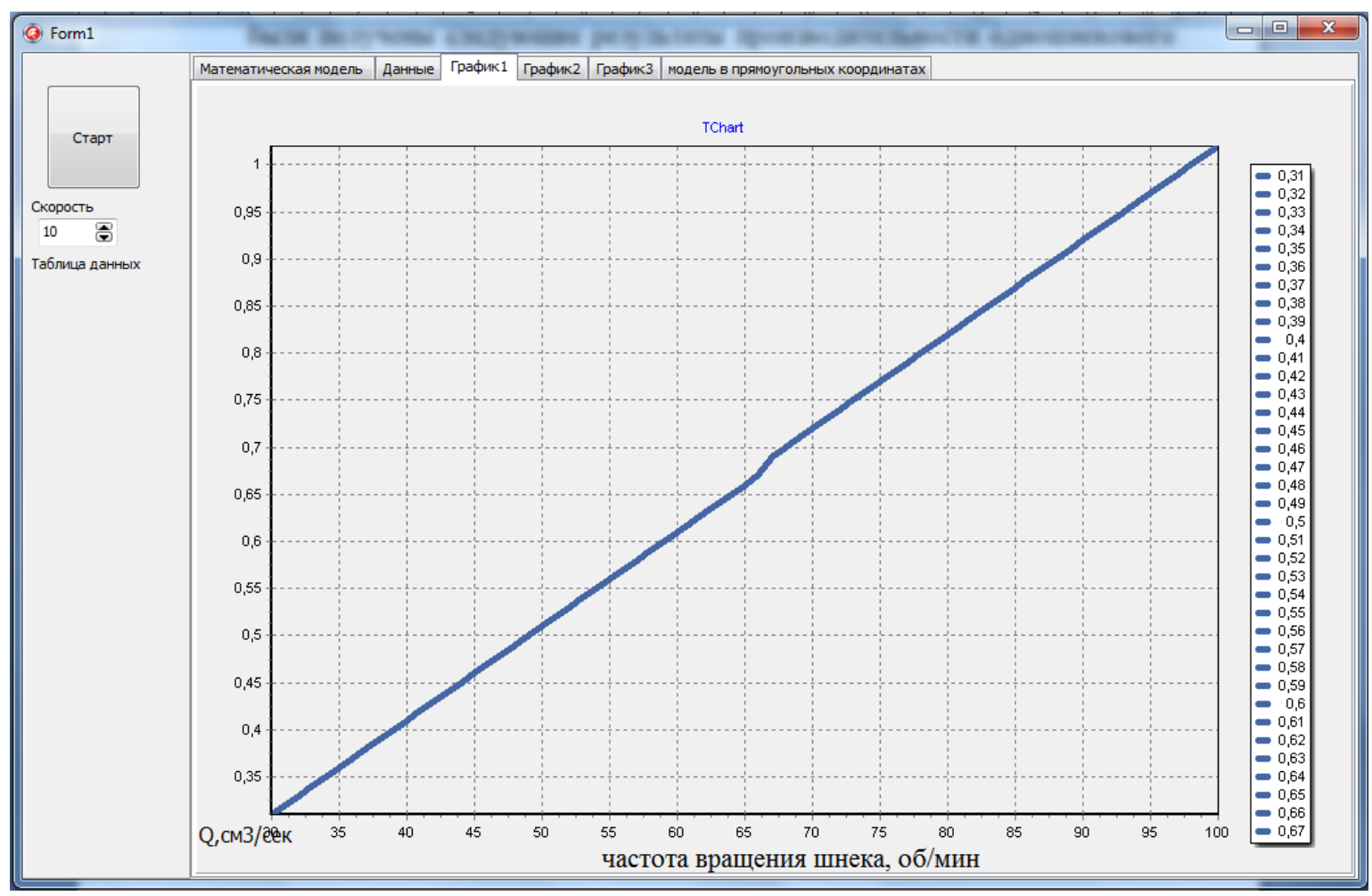

Рисунок 6 - Зависимость объемной производительности экструдера от частоты вращения шнека 


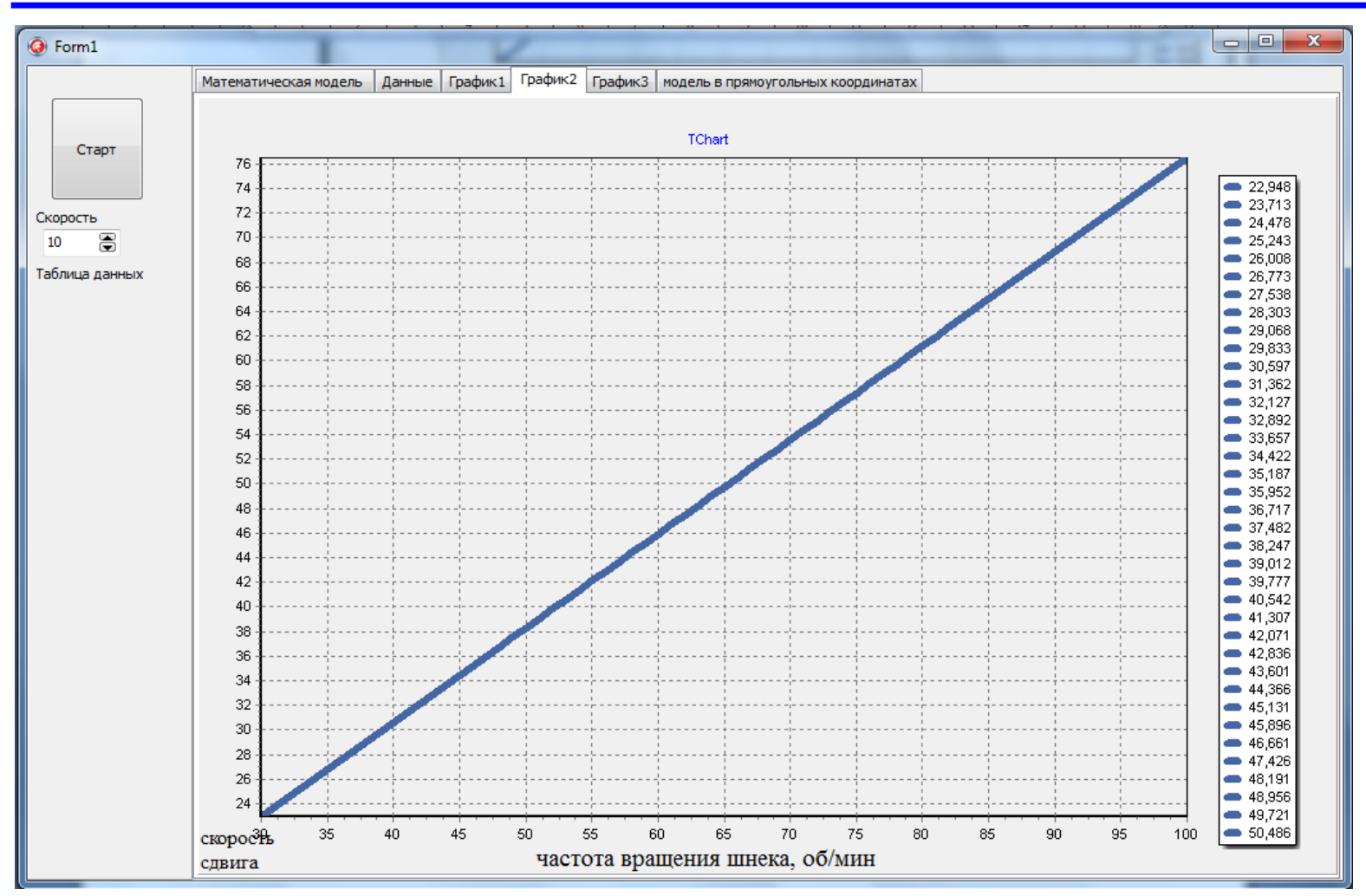

Рисунок 7 - Зависимость скорости сдвига расплава в канале шнека от частоты вращения шнека

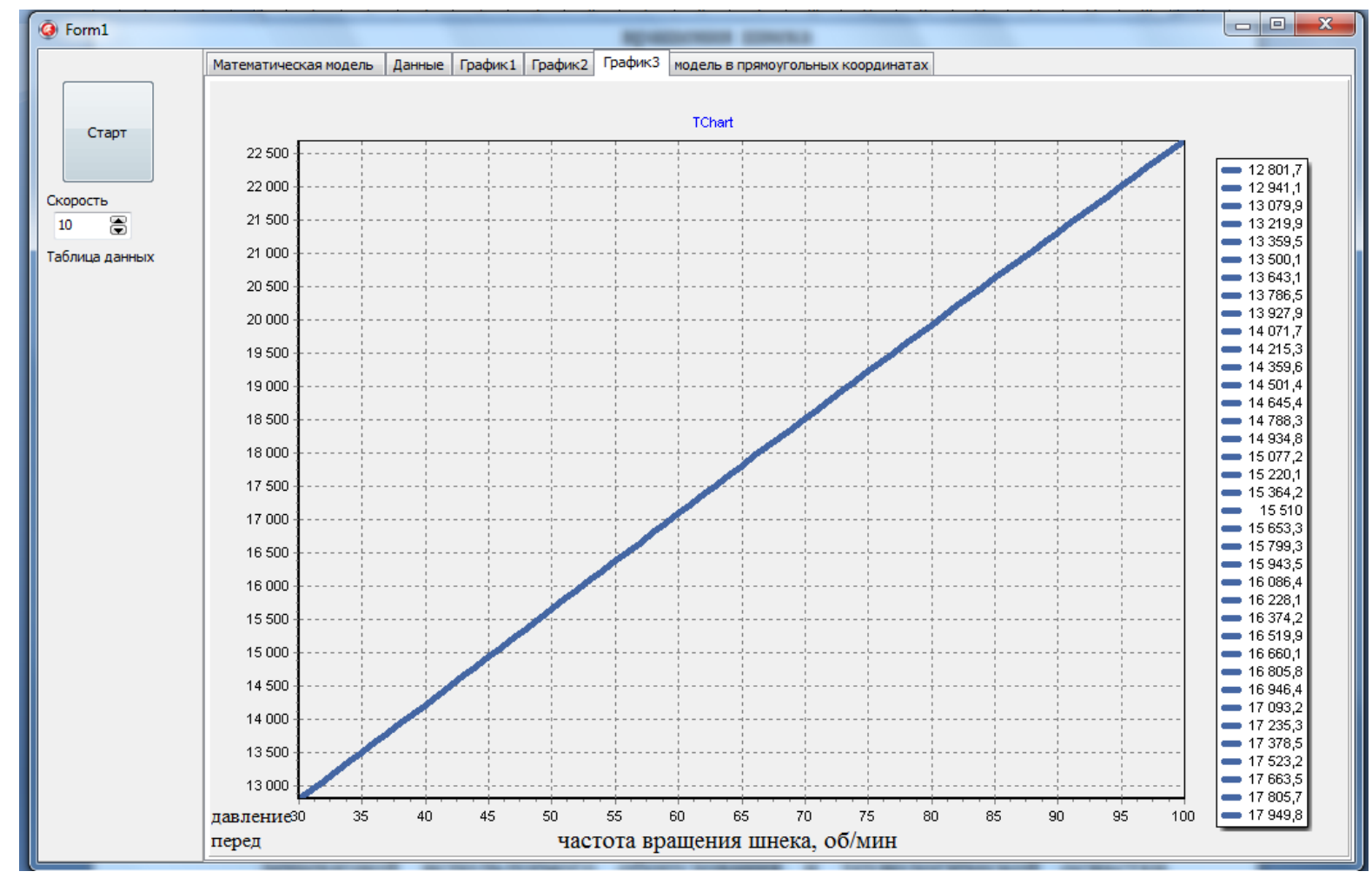

Рисунок 8 - Зависимость максимального давления расплава от частоты вращения шнека 


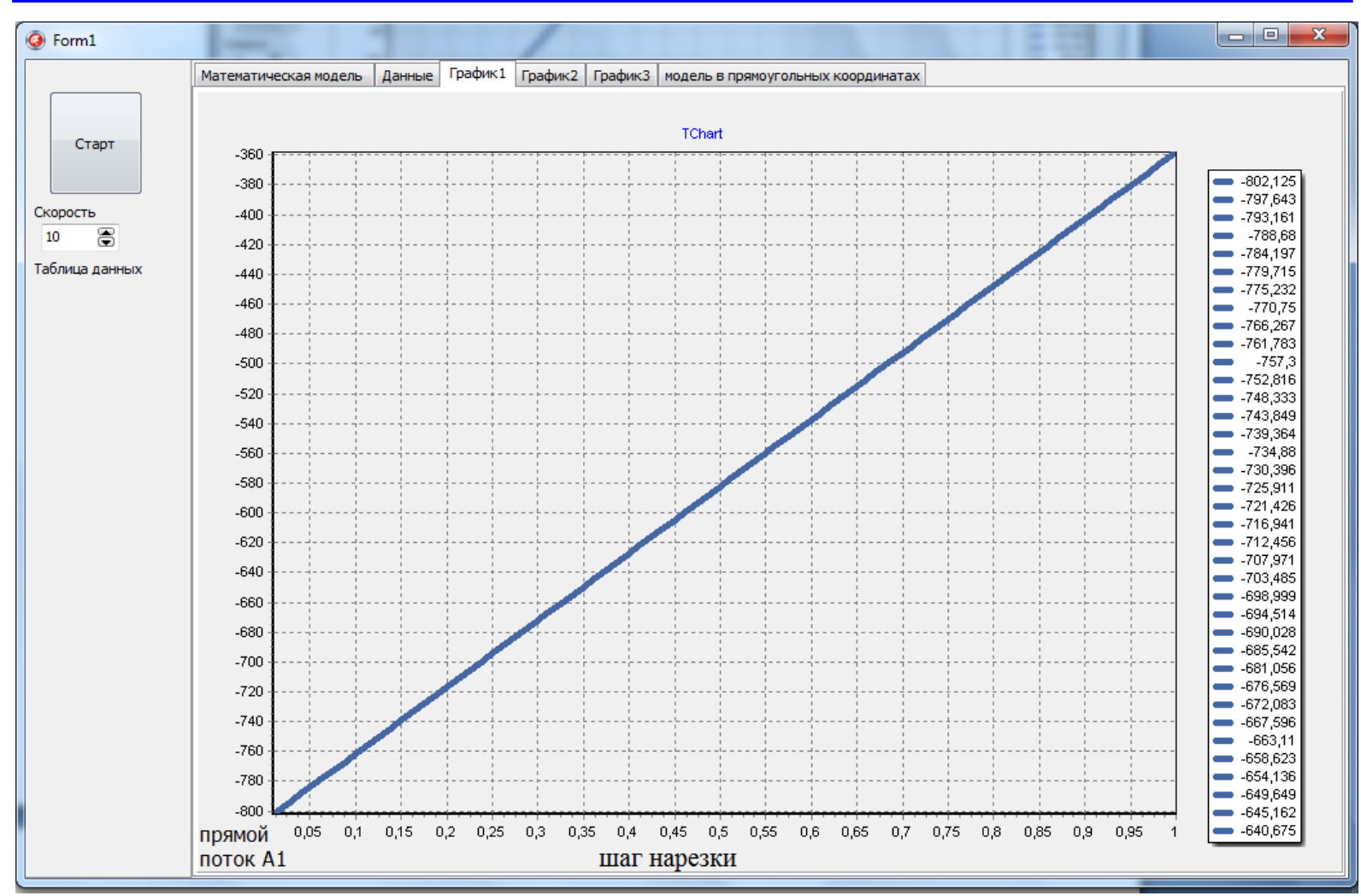

Рисунок 9 - Зависимость постоянной прямого потока от шага нарезки

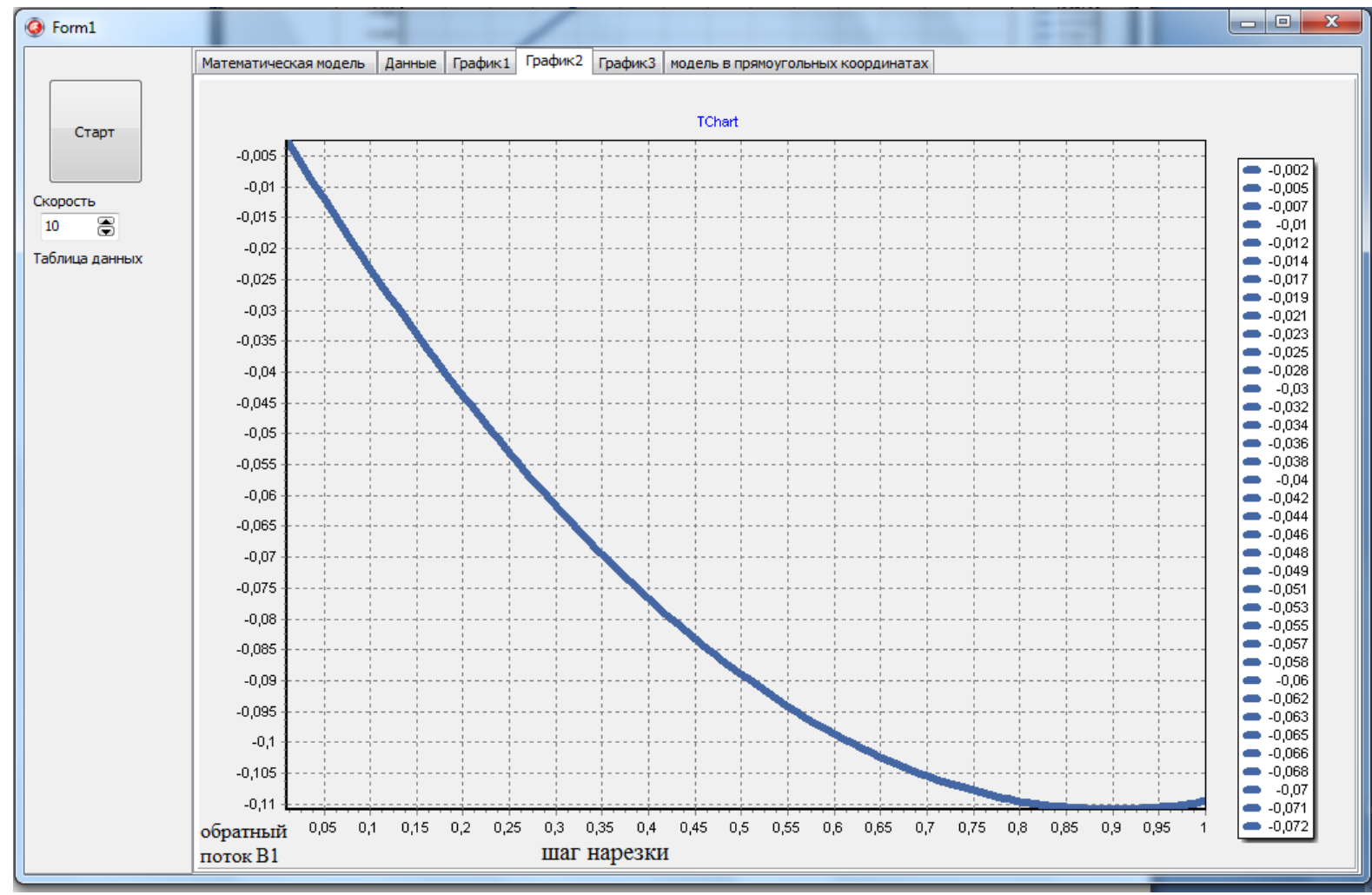

Рисунок 10. Зависимость постоянной обратного потока от шага нарезки 
В процессе выполнения данного исследования нами были рассмотрены процессы переработки полимерных материалов: термоформование и экструзия. Термоформование получило широкое распространение благодаря простоте, компактностью, относительной дешевизной используемого оборудования и технологической оснастки. Экструзия широко применяется в различных отраслях промышленности для переработки разнообразных полимеров и композиционных материалов. Экструзией из пластических масс изготавливают трубы, листы, плиты, панели, пленки, электрические кабели и различные виды профильных изделий, как малых, так и больших сечений.

Нами были рассмотрены особенности данных технологических процессов, изучены численные методы решения уравнений моделей, и на их основе разработаны блок-схемы решения задач. На основании разработанных алгоритмов решения было выполнено решение поставленных задач при помощи среды программирования Delphi.

Разработанные алгоритмы и программы позволяют на основе ММ процессов подготовки расплава в экструдере и формообразования пленочного рукава и ММ для оценки качества экструдата и пленки решать задачи перенастройки экструзионной линии на новые характеристики производства и управления качеством пленки для различных типов пленок, типов и конфигураций экструдеров, требований к производительности и качеству пленки. Применение системы моделирования позволит повысить конкурентоспособность производителей высокотехнологичных упаковочных и гигиенических полимерных пленок за счет роста качества продукции, снижения брака при перенастройке линии на другой тип пленки, производительность, экономии дорогостоящего сырья, уменьшения временных и финансовых затрат на проведение натурных экспериментов при освоении производства пленок новых рецептур.

\section{References:}

1. Басов Н. И., Казанков Ю. В. Литьевое формование полимеров. - М.: Химия, 1984. - $248 \mathrm{c.}$

2. Ведь Г. И., Сенатос В. А., Петухов А. Д. Определение напряжений при формовании рукавной пленки // Химическая технология. - 1979. - № 4. - С. 34-37.

3. Воскресенский А. М., Ищенко М. А. Компьютерные модели свойств и переработки полимерных композиций. - СПб.: СПбГТИ (ТУ), 2008. - 66 с.

4. Воскресенский А. М., Кучинская Е. А. Переработка полимерных материалов в червячных машинах. Методы технологических расчетов. - СПб.: СПбГТИ (ТУ), 2000. - $58 \mathrm{c}$.

5. Воскресенский А. М., Сыкалов Г. В. Метод итераций вязкости в теории переработки полимеров. - СПб.: Изд-во СПбГТИ(ТУ), 2013. - 116 с.

6. Лукач Ю. Е., Петухов А. Д., Сенатос В. А. Оборудование для производства полимерных пленок. - М.: Машиностроение, 1981. - 224 с.

7. Полосин А. Н. Моделирование и оптимизация процессов смешения термопластичных материалов в одношнековых экструдерах // Информационные технологии моделирования и управления. - 2009. - № 2. - С. 297-305.

8. Полосин А. Н., Плонский В. Ю. Расчет термической деструкции полимерного материала в осциллирующем экструдере // Информационные технологии в науке, проектировании и производстве: материалы V Всерос. науч.-техн. конф. Н. Новгород: Межрегион. Верхне волж. отд-ние Акад. технол. наук РФ, 2002. C. 13-14.

9. Полосин А. Н. Технология моделирования неизотермического течения расплавов полимеров в одношнековых экструдерах на базе теории плоских 
потоков // Информационные технологии моделирования и управления. - 2007. — № 3. - С. 376-386.

10. Полосин А. Н., Чистякова Т. Б. Математическая модель одношнековой экструзии для управления качеством пластиката в многоассортиментных производствах полимерных пленок //Системы управления и информационные технологии. - 2009. - № 2. - С. 87-92.

11. Полосин А. Н., Чистякова Т. Б., Блинов И. Г. Библиотека математических моделей для исследования и перенастройки процессов получения рукавных пленок // Математические методы Программный комплекс для моделирования и оптимизации одношнековых экструзионных процессов в многоассортиментных производствах пленочных и гранулированных полимерных материалов : свидетельство о гос. рег. программы для ЭВМ № 201061423

12. (30.06.2010) / Чистякова Т. Б., Полосин А. Н., Григорьев О. Е. // Программы для ЭВМ. Базы данных. Топологии интегральных микросхем: офиц. бюл. Федер. службы по интеллект. собственности, пат. и товар. знакам. - М.: ФИПС, 2010. - Вып. 3. - С. 447.

13. Раувендааль К. Экструзия полимеров. - СПб.: Профессия, 2008. - 768 с.

14. Тадмор 3., Гогос К. Теоретические основы переработки полимеров. - М.: Химия, 1984. -632 с.

15. Тарасик В. П. Математическое моделирование технических систем. 2-е изд., испр. и доп. -Мн.: ДизайнПРО, 2004. - 640 с.

16. Торнер Р. В. Основные процессы переработки полимеров (теория и методы расчета). - М.:Химия, 1972. - $456 \mathrm{c.}$

17. Торнер Р. В. Теоретические основы переработки полимеров (механика процессов). - М.: Химия, 1977. - 464 с.

18. Чистякова Т. Б., Полосин А. Н. Методы и технологии синтеза математических моделей процессов экструзии в гибких производствах полимерных материалов // Вестник Саратовскогогосударственного технического университета. - 2011. № 4. - C. 170-180.

19. Чистякова Т. Б., Полосин А. Н., Блинов И. Г. Программный комплекс для моделирования процесса раздувной экструзии полимерных материалов при изготовлении высокотехнологичных пленок // Высокие технологии в производстве и переработке полимерных материалов: сб. тр. VI Междунар. науч.-техн. конф. СПб.: СПбГТИ(ТУ), 2012. — С. 52-65.

20. Лахтин Ю. М., Леонтьева В. П. Материаловедение: Учебник для высших технических заведений. - 3-е изд., перераб. и доп. - М.: Машиностроение, 1990.

21. Материалы будущего: перспективные материалы для народного хозяйства. Пер. с нем./ Под ред. А. Неймана. - Л.: Химия, 1985.

22. Тарнопольский Ю. М., Жигун И. Г., Поляков В. А. Пространственноармированные композиционные материалы: Справочник. Машиностроение, 1987.

23. Политехнический словарь. Гл. ред. И. И. Артоболевский. - М.: «Советская энциклопедия», 1977.

24. Композиционные материалы. [Электронный pecypc] URL: http://365tv.ru/index.php/stati/innovatsii/356-kompozitsionnye-materialy-perspektivyprimeneniya (дата доступа: 20.05.2014).

25. Композиционные материалы [Электронный pecypc] URL: www.issep.rssi (дата доступа: 20.05.2014).

26. Космические композитные материалы займутся самолечением [Электронный pecypc] URL: www.elementy/news/ (дата доступа: 20.05.2014). 
27. Сверхзвуковые самолеты, космические летательные аппараты, баллистические ракеты [Электронный pecypc] URL: www.krugosvet/ (дата доступа: 20.05.2014).

28. Карслоу Г., Егер Д. Теплопроводность твердых тел. М., "Наука", 1964. 487 с.

29. Годовский Ю.К. Теплофизические методы исследования полимеров. - М., Химия - 1976.

30. Тябин Н. В. и др. В кн.: Теплообмен. 1974. Советские исследования. М., "Наука", 1975, с. 195-198. 